\title{
Investigación científica durante la carrera de medicina ¿Realmente cumple nuestras expectativas?
}

María Ximena Rodriguez Alvarez ${ }^{2}$

$\mathrm{L}$ a investigación científica constituye uno de los pilares esenciales de la ciencia, más aún del área médica. Estos últimos años la escasez de trabajos ha resultado ser una gran preocupación para editores de Revistas Científicas, sobre todo en un país como Bolivia. El decaimiento de la producción científica puede deberse a la falta de motivación derivada del insuficiente conocimiento de la metodología científica ${ }^{1}$.

En el primer año de la carrera, los estudiantes entran con grandes expectativas siendo una de ellas el aprender y adquirir práctica en el ejercicio de la medicina, pero al parecer con el paso de los años se abandona ésta motivación, que impulsaba a estudiar medicina. Las razones de cada estudiante van desde estudiar para servir a la comunidad, motivos personales, motivos académicos e incluso por el reconocimiento profesional y la remuneración económica. Una vez dentro la carrera se asimila el interés de la producción de trabajos científicos para el continuo aprendizaje y para el desarrollo profesional, pero las actividades académicas así como la escasez de tiempo impiden dicho proposito ${ }^{2}$.

Se piensa o se tiene la idea equivocada de que la investigación es realizada por personas expertas en el campo o es una actividad académica producto de la exigencia de algunas materias y ciertos docentes, pero en realidad los trabajos de investigación son realizados por personas que buscan y desean ir más allá para desvelar la verdad e ir en contra los prejuicios impuestos por la ignorancia. Puesto que al buscar, al investigar y redactar una hipótesis se intenta dar una posible explicación al problema.

Lo maravilloso de la investigación es que durante el curso del trabajo descu- bres que la lógica a veces no es lo que dice ser, se desmoronan esquemas del pensamiento producto de la tradición y de la comodidad que ataca cada profesión.

Por ser estudiante y por la misma carrera se supondría que la producción y publicación de artículos científicos es intensa, porque se considera que un médico es un científico que investiga, es decir hace ciencia y la practica.

Pero según varios estudios el sistema de prejuicios limita, creyendo que investigar es asunto de algunos, además se percata una baja motivación, evidenciando que son pocos los docentes que investigan e imparten una educación médica basada en éstos hechos ${ }^{2,3}$.

Se puede culpar al sistema y buscar otras falencias, pero los responsables directos radican en uno mismo, siempre estarán las excusas de un examen, la falta de tiempo, de que no existan docentes que encaminen al arte de investigar o pueda posponer una investigación no valorando su importancia. Parece que las circunstancias no son favorables, y a pesar de contar con varios recursos tecnológicos cada vez la calidad de investigación, la repetición de trabajos y la escasez de los mismos son parte ya de la odisea de los editores.

La motivación es al parecer un componente faltante y para nada fácil de obtenerlo, porque está relacionado con las creencias y el contexto mismo de los estudiantes ${ }^{3}$.
Maria Ximena Rodriguez Alvarez ${ }^{1}$
${ }^{1}$ Estudiante de Medicina, Directora de redacción,
Revista Científica Ciencia Médica, Facultad de
Medicina Universidad Mayor de San Simón,
Cochabamba, Bolivia.
Correspondencia a:
xim.keane@gmail.com

Referencias:

1. Carrillo-Larco M.R., Carnero A.M., Autoevaluación de Habilidades Investigativas e Intención de dedicarse a la investigación en estudiantes de primer año de medicina de una universidad privada en Lima, Perú. Rev Med Hered. 2013; 24:17-25 Disponible en: http://www.scielo.org.pe/pdf/rmh/v24n1/ v24n1ao3.pdf Acceso 14 de junio de 2014.

2. González A.K., Insuficiente conocimiento de la metodología establecida para la elaboración y publicación de artículos científicos. REMIJ 2011; 12(2): Disponible en: http://www.remij.sld.cu/index.php/remij/article/ view/19/45 Acceso 15 de junio de 2014.

3. Steinmann A., Bosch B., Aiassa D. Motivación y expectativas de los estudiantes por aprender ciencias en la universidad. Revista Mexicana de Investigación Educativa, 2013; vol. 18(57): 585-598. Disponible en: http://www.redalyc.orgpdf/140/14025774012. pdf Acceso 14 de junio de 2014. 